\title{
BMJ Open Mantra meditation programme for emergency department staff: a qualitative study
}

\author{
Julie Lynch, ${ }^{1}$ Lucia Prihodova, ${ }^{1}$ Pádraic J Dunne, ${ }^{2}$ Caoimhe O’Leary, ${ }^{1}$ \\ Rachel Breen, ${ }^{1}$ Áine Carroll, ${ }^{3}$ Cathal Walsh, ${ }^{4}$ Geraldine McMahon, ${ }^{5}$ Barry White ${ }^{1,2,6}$
}

To cite: Lynch J, Prihodova L, Dunne PJ, et al. Mantra meditation programme for emergency department staff: a qualitative study. BMJ Open 2018;8:e020685. doi:10.1136/ bmjopen-2017-020685

- Prepublication history and additional material for this paper are available online. To view these files, please visit the journal online (http://dx.doi. org/10.1136/bmjopen-2017020685).

Received 17 November 2017 Revised 8 June 2018 Accepted 13 August 2018

Check for updates

(c) Author(s) (or their employer(s)) 2018. Re-use permitted under CC BY-NC. No commercial re-use. See rights and permissions. Published by BMJ.

${ }^{1}$ Research Department, Royal College of Physicians of Ireland, Dublin, Ireland

${ }^{2}$ Trinity Translational Medicine Institute, St James' Hospital Campus, Trinity College Dublin, Dublin, Ireland

${ }^{3}$ Clinical Strategy and

Programmes Division, Health

Service Executive, Dr Steevens'

Hospital, Dublin, Ireland

${ }^{4}$ Health Research Institute,

University of Limerick, Limerick, Ireland

${ }^{5}$ Department of Emergency Medicine, St James' Hospital, Dublin, Ireland

${ }^{6}$ National Coagulation Centre, St James' Hospital, Dublin, Ireland

Correspondence to Julie Lynch; lynchju@tcd.ie

\section{ABSTRACT}

Objectives Rates of burnout and stress in healthcare practitioners are steadily increasing. Emergency department (ED) staff are particularly susceptible to such poor outcomes. Mantra meditation (MM) may contribute to increased well-being. The primary aim of this study was to obtain indepth qualitative feedback on ED staff's experience of a MM programme. A secondary objective was to harness staff's perception of the ED working environment.

Design Qualitative study.

Setting ED in St James' Hospital, Dublin, Ireland. Participants Doctors, nurses, allied health professionals and administrative staff ( $n=10$, eight women, mean age 35.6 years) working in the ED who attended a MM programme.

Methods Semistructured interviews were conducted by a trained independent researcher. Interviews were transcribed and thematically analysed.

Results Five main themes and six subthemes were identified: work pressure and perceived stress; perceived benefits of meditation (with subthemes of increased attention/awareness, improved emotion regulation and new coping mechanisms, relaxation and sleep quality); conflicting attitudes to practice; barriers to meditation practice (with subthemes of schedule, length of practice and individual differences); and facilitators to practice.

Conclusion ED staff in this study described the demands of their work and voiced a need for a workplace well-being programme. Our findings suggest that MM might represent a viable tool to develop attention and awareness, improve emotion regulation and improve their capacity to cope with stress, which may impact their workplace well-being, wider health service, patient safety and quality of care. Support from the organisation is considered to be integral to embedding of a workplace well-being programme, such as the practice of meditation into their daily lives.

\section{INTRODUCTION}

The prevalence of burnout among healthcare practitioners (HCPs) exceeds that of any other professional working group. ${ }^{12}$ Emergency medicine doctors in particular report the highest percentage of burnout of 25 different healthcare specialties in a large-scale US study, ${ }^{3}$ with similar findings documented

\section{Strengths and limitations of this study}

- Indepth interviews offered an exclusive insight into the personal experiences of mantra meditation from the perspective of emergency department staff.

- The study used a validated qualitative approach (thematic analysis) to analyse the rich and complex data, thus contributing important new insights to existing research on the benefits of meditation for healthcare practitioners.

- The findings from participant interviews highlight potential issues of feasibility in implementing a well-being programme for emergency department staff, and provide a unique insight into what works and what does not for future research in occupational health interventions.

- Adherence to mantra meditation practice was not consistent across participants, which must be taken into consideration when interpreting the results.

in Ireland. ${ }^{4}$ The implications of such a working environment are detrimental and include compassion fatigue, cynicism, ${ }^{5}$ depression $^{6}$ and even suicide. ${ }^{78}$ The adverse consequences extend far beyond the wellbeing of the individual, and are reported to have a wider impact on patient safety, quality of care, ${ }^{9-12}$ absenteeism ${ }^{13}$ and early retirement, ${ }^{14} 15$ thus making it an issue of critical importance not only for the HCP, but for all stakeholders involved in healthcare delivery.

There are numerous studies on the various sources of stress for doctors, nurses and allied health professionals (AHPs) working in the emergency setting; however, studies on interventions to offset this occupational stress are scarce. In the general population, there is evidence to support the benefits of meditative practice (among other mindbody interventions such as mindfulness and yoga), and its potential to positively impact the health and well-being of HCPs is being increasingly recognised. A recent US study of HCPs undertaking a 'Heartfulness Meditation' programme demonstrated significant 
improvements in all measures of burnout following a 12-week course. ${ }^{16}$ Significant reductions in stress and anxiety were also reported in nurses after a 1-month biofeedback-assisted meditation programme. ${ }^{17}$

Mantra meditation (MM) or mantram repetition (which includes Transcendental Meditation) involves the act of repeating a word or phrase, silently or aloud, and is considered an ancient practice with roots in spiritual traditions. Recently, MM has emerged as a 'rapid-focus tool' for training attention and calming the mind. ${ }^{18}$ It has been suggested that MM offers a number of practical advantages over other types of mind-body interventions, including simplicity and portability. ${ }^{19} \mathrm{MM}$ has been employed as an intervention to limit stress in healthcare workers in a small number of studies, resulting in improvements in self-reported spiritual well-being, mindfulness traits, stress, anxiety, anger and quality of life. ${ }^{20-22}$ Such workplace health programmes have been identified by the WHO as one of the 'best buy' options for mental health and well-being of employees. ${ }^{23}$ Nonetheless, rigorous evaluation is essential if such interventions and programmes are to be successfully integrated into the busy working environment and lives of HCPs. The acquisition of indepth qualitative feedback is considered to be a crucial aspect of this process, complementing and enhancing the quantitative evaluation by providing enriched understanding and descriptions of personal experiences of MM, as it is situated and embedded in a local context. ${ }^{24}$ Qualitative syntheses exploring healthcare workers' experiences of mindfulness training have been conducted $^{26}$; thus it is considered timely and appropriate to acquire similar qualitative feedback from HCPs for MM.

\section{Study objectives}

The primary objective of this study was to qualitatively evaluate a MM programme in an emergency department (ED) setting by harnessing participants' experience and perceived impact of the programme. A secondary objective included identifying staffs' perception of their working environment.

\section{METHODS}

Design

This qualitative study was conducted in parallel to a randomised controlled trial (RCT) investigating the effect of MM on quantitative indicators of burnout, as well as psychological and physiological markers of health in ED staff.

The data collection for this qualitative study-individual, semistructured interviews-was conducted in the study participants' workplace within 8 weeks of the final session of the MM programme by a member of the research team $(\mathrm{CO}$ 'L). The interviews followed a topic guide (table 1); the open-ended format of the interviews was selected in order to thoroughly explore participants' experience and perception of the programme. The length of interviews ranged from 16 to $58 \mathrm{~min}(\mathrm{M}=38.28, \mathrm{SD}=11.91)$. Participants were advised that they could withdraw from the study at any time and were informed that all transcripts would be anonymised.

\section{MM programme}

The objectives of the MM programme were to teach participants the basic principles and practice of MM in their workplace and to support the embedding of the practice of MM in their daily lives. The programme consisted of four sessions (each 4 hours long) and was delivered in the hospital over a 6-week period. Each session followed a structured manual and combined meditation practice, talks on different aspects of meditation (ie, physical preparation for meditation, dealing with distractions,

\begin{tabular}{ll}
\hline Table 1 Topic guide & \\
\hline Interview topics & Sample questions \\
\hline Rapport-building & Can you tell me a bit about your role in the emergency department? How would you describe your \\
& Work? \\
& What was your motivation for taking part in the meditation programme? \\
Impact of meditation & What has work been like for you since taking part in the programme? \\
programme on self & If you were to compare yourself before and after taking part in the programme, what observations \\
& would you make, if any?
\end{tabular}


being and doing) and discussion of contemplative texts related to meditation practice and the meaning of healthcare (see online supplementary file 1). Additionally, participants were asked to meditate independently for 20 min twice a day (preferably morning and evening). The mantra used in this programme was maranatha, broken into four syllables: ma-ra-na-tha. The MM programme was developed and cofacilitated by a healthcare expert and a meditation expert in 2013 and was originally delivered in a classroom setting. The established MM programme was adapted to be delivered in the workplace. Neither of the facilitators were involved in any elements of the research study, for example, data collection, analysis or interpretation.

\section{Participants and recruitment}

As part of an ongoing RCT, ${ }^{27} 17$ members of the ED staff (10\% of the department) were assigned to an intervention group to attend a MM programme. Participation in the RCT (and subsequently the programme) was voluntary and free of charge, and the programme was delivered during working hours. Attendance rates for the whole group varied over the course of the programme $(77 \%$, $100 \%, 59 \%$ and $41 \%$ for sessions $1,2,3$ and 4 , respectively). All 17 staff members were invited to take part in the qualitative study. Ten participants agreed to participate in the qualitative aspect of the study. The sample was generally representative of the gender and age breakdown (eight women, mean age 35.6 years), the roles (eg, nurse practitioner, emergency doctor, AHP) and length of ED experience ( 9 months to 17 years) of the wider ED department. Attendance rates did not differ substantially between those who agreed to interview (mean attendance rate: $65 \%$ ) and those who did not (mean attendance rate: $65.63 \%$ ). Further breakdown of individual participant characteristics will not be provided to preserve anonymity. While a greater sample size would have been favourable, on completion of all 10 interviews, data saturation was achieved.

\section{Data analysis}

Interviews were audio-recorded and transcribed verbatim by a professional transcription service. The transcription was checked by a member of the research team to remove any identifiable information, and participants were offered the opportunity to review their transcripts. QSR International's NVivo V.11 (qualitative data analysis software) was used to store and analyse the data. Thematic analysis methodology ${ }^{28}$ guided the analysis of data (conducted by JL) and involved familiarisation with the data, generating initial codes, searching for themes, reviewing and refining themes, and defining final themes. A second member of the research team (LP) coded an interview transcript independently to assess inter-rater reliability, and differences in the interpretation of the data were discussed. Agreement was high in the comparison of codings. Minor editing of the quotes was performed to ensure clarity of meaning and to preserve anonymity.
Overall, the research team was multidisciplinary, but both researchers involved in data analysis had backgrounds in psychology. Researchers conducting the data analysis (JL and LP) were experienced in qualitative data analysis and entirely independent from the MM programme to avoid confirmation bias.

\section{Patient and public involvement}

Extensive stakeholder consultation (which included a senior staff member of the emergency medicine department) on the design of the MM programme and the research study was conducted. There was no patient or public involvement in the recruitment process. The study findings will be disseminated to all study participants by way of email, in an appropriate, reader-friendly format. The final published manuscript will be made available to participants and relevant stakeholders on request.

\section{RESULTS}

Thematic analysis identified five prominent themes in the data: (1) work pressure and perceived stress; (2) benefits of meditation practice; (3) conflicting attitudes to practice; (4) barriers to practice; and (5) facilitators to practice (see table 2).

\section{Theme 1: work pressure and perceived stress}

Work pressure and perceived stress were a highly prominent theme, with every participant reporting on the pressure of their work environment encountered on a regular basis, and the need for a wellness programme to be implemented in the ED and in pan-hospital. This was further reflected in comments and discussions about the complexities and tragedies of patients presenting to the ED on a daily basis.

Several participants made reference to the nature of uncertainty that pervades the ED on any given day; HCPs often experience 'an element of impending doom' or anxiety prior to their work shift. It was acknowledged that death in the ED (which is almost always sudden and unexpected) can be particularly difficult to manage, and that while patients are being attended to for their physical injuries they tend to disclose their own personal stories and issues onto the HCP.

There is huge complexities behind all of their stories...you might have...addressed their injury but then there is the whole [story], you are kind of counselling nearly, I find in this job you are counselling a lot and I suppose that is probably part and parcel of what the HCP does and that development of that relationship you have with your patients but it can get very heavy at times with what they are telling you, you know.

The ED working environment was regularly cited as taxing, with most participants referring to sheer exhaustion, poor sleep patterns, the department being 


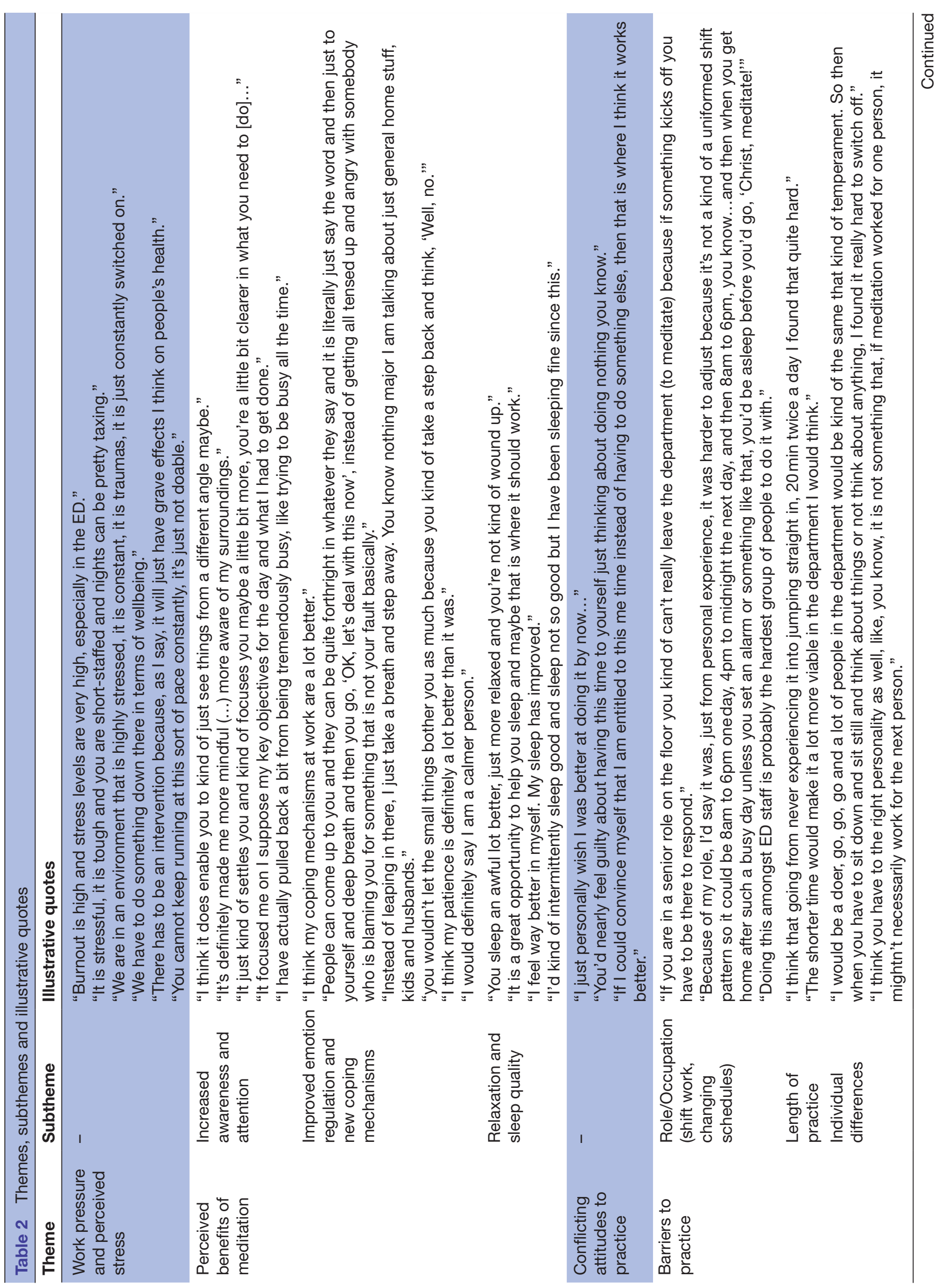


understaffed, difficulty adjusting to shift work and just constantly feeling 'switched on'.

You go home and you are either absolutely wired or you crash and burn and you don't intervene and then you're kind of tossing and turning, nearly anxious waiting for the next day. Then you get up and do it all again.

It was noted by several participants that staff are torn in different directions and that stress emanating from one person often eventually filtered around to everybody else, from reception staff and cleaners to doctors and nurses. Generally, every participant recognised the need for a programme of support for the ED staff.

You can't keep running at a certain pace without intervening because as I say, it is like a marathon, you come in and you face the same thing every day, day in day out and you will burn if you don't mind yourself and you don't take care of yourself.

You can't maintain that without having either some mental or physical effects.

The working environment of the ED lends itself to staff burnout and exhaustion, to such an extent that some members of the staff noted that 10 years is the maximum amount of time you can give to the profession. Participants reported poor work-life balance and found it difficult to 'cease the chatter' of their minds when they return home.

\section{Theme 2: perceived benefits of meditation}

In discussing their experience of the meditation programme, staff cited a myriad of benefits in both their personal and professional lives. These have been further broken down into subthemes of attention and awareness, emotion regulation/coping skills and sleep.

\section{Increased attention and awareness}

One of the key personal benefits that arose among participants was a sense of heightened situational awareness. They felt better equipped to see things from a different angle, as well as an improved awareness of themselves.

I was always one to say, 'I'm not stressed, I'm not stressed', through clenched teeth and believe it. Whereas now I'm saying, 'Hang on, I'm very stressed and I'm taking it out on...'.

Participants discussed how the programme and practice of meditation helped them to refocus, particularly when faced with a long shift where priorities and objectives had to be decided on. This sense of attention and 'refocusing' was also echoed in their interactions with patients, and the process of moving from one patient within emergency to another.

I think hopefully this will improve recovery...you're dealing with an emergency that has been dealt with and they move on, but I need to be able to (move 
on) and it is about me, I need to be able to recover quickly, so I can give the next patient my full attention. Because I know sometimes if I am worried about somebody, I will be distracted with the next patient. So I felt this would actually help my recovery as such, so that I will have full attention for the next patient.

This renewed attention and awareness of themselves and their surroundings extended to a more favourable work-life balance for some.

I sort of got a bit too sucked in to work and I found it very hard to escape it really. I felt my whole world was dominated by my job and now that has kind of stopped.

\section{Improved emotion regulation and new coping mechanisms}

Participants noted an improvement in coping with a hectic life at home and at work, as well as the cultivation of a more patient attitude.

It grounded me I suppose is a better word, but it calmed me. So even though like I think I have hundred and one jobs to do, it kind of calmed me and when I do it at work, it calms me...

Some participants discussed improved coping mechanisms while at work, and feeling more competent at managing emotionally laden, stressful, emergency situations.

I used to get emotional when stuff would come in to Resuscitation, but now I kind of...I think I have just learned to manage it better.

\section{Relaxation and sleep quality}

An improvement in quality of sleep was reported by many of the participants, both for those with regular and irregular shift patterns.

What I have observed is that I think on the days that I am working, say if I am working today and I was working tomorrow, I don't really sleep very well. And certainly I think this is intervened, I definitely sleep better.

\section{Theme 3: conflicting attitudes to practice}

Despite myriad accounts of the benefits of meditation on participants' personal and professional lives, some participants noted conflicting attitudes they experienced towards the practice of meditation. Such feelings (predominantly associated with guilt) arose due to not engaging successfully with the practice, or alternatively due to taking the time out to engage in the practice when there were other jobs to be done.

I am just really disappointed in myself that I didn't put more effort in to the meditation...
You still feel guilty sometimes, taking time out like that when there is stuff to be done or work to be done...

There was also a distinct sense of staff feeling responsible for leaving work colleagues short-staffed, when attempting to meditate during work hours.

You've also got that kind of little niggle in the back of your head saying, 'There's one specialist trainee doctor back there with a junior doctor and the department is heaving. So it's nice that I can get to this but, you know, our brothers in arms are back there at the coal-front fighting on six different fronts when we could have made it three', kind of thing.

\section{Theme 4: barriers to practice}

Participants reported several major barriers to practising meditation: the practicalities of their role (ie, shift work, changing schedules), the recommended length of practice, and the typical profile or personality of an HCP.

\section{Shift work/changing schedules}

The role of the individual in the ED and the practicalities of their contract (ie, long working hours, night shifts, changing schedules) were proposed as a barrier to developing regular practice by most participants. For majority, uniform shift patterns are not common for ED staff, making it difficult for them to incorporate daily meditation into their schedule as a concrete habit. Similarly, the strenuous work environment inevitably results in fatigue, which also poses a barrier to an evening practice.

...When we came home it could be half nine or ten o'clock, you are prepping your food for the following day if you were in the following day...but sometimes you go home and you are just flat like, you are just exhausted and you are kind of there opening your eyes partly wondering how long is left on the timer.

...There was a period at work where things were just mental and that fatigue hits in, and you are just like, 'Oh no I will do it tomorrow'.

The unpredictable nature of work in the ED means that it is not feasible to dedicate protected time to meditate during the working day as staff are expected to be close by the department at any given time in case their services are urgently required.

\section{Length of practice}

Each participant expressed at least some difficulty in maintaining the twice daily $20 \mathrm{~min}$ meditation practice as advised by the programme facilitators, and several participants commented that adherence to the practice was driven by their participation in the study, rather than actually contributing towards their own health. Participants reported difficulty staying with the meditation for the full $20 \mathrm{~min}$, as well as difficulty finding an appropriate time period during the day in which to fit the practice. Several participants recommended that the practice be 
gradually built up over time, perhaps starting with $5 \mathrm{~min}$ twice a day or $10 \mathrm{~min}$ once a day.

It's like training for something...you are not going to go off and do a 10K [run] if you can't do that or if you know that you don't have the time to do it, so start off with doing something achievable and then build on it.

It was suggested that this would encourage the development of a more sustainable and feasible practice for novice meditators.

\section{Individual differences}

It was notable that many of the staff considered themselves to be highly active, outgoing individuals, and they felt this contrasted with what was being asked of them in meditation practice.

I think we have all got similar personality types and you know of being fast paced, busy you know go, go, go, I think we are probably the hardest group you will find to switch off a little bit.

An interesting concept was brought to light by one participant who explained that what drew them to working in that kind of an environment in the first place was the very thing that was preventing them from committing to meditative practice.

I think what led me to Emergency was what stood against me delving fully into mantra meditation, as in sitting still and not focusing. Whereas I like to be kind of hypermobile in the department, if I'm sitting for more than five min I have to get up and check another patient or do that. So it was the actual disconnect that I was like, 'Woah hang on, I'm not used to this'.

There was a distinct sense from the transcripts that participants believed certain people 'fit the bill' for meditation, whereas others did not. Those who 'fit the bill' tended to be described as more easy-going, with mellow personalities.

There are a huge amount of different personalities in the ED, the majority of them are really strong, opinionated, loud personalities, you know and I don't know if meditation would suit everybody.

\section{Theme 5: facilitators to practice}

A strong desire to continue with daily meditation practice and a wish to thoroughly integrate meditation into the workplace was clearly evident throughout the interviews. In discussing factors that facilitated their practice and factors that would enable them to continue this practice, participants spoke primarily of support from the organisation and support from each other.

\section{Organisational support}

Support from the organisation (ie, the hospital) was broken down by participants and generally fell into the category of either protected time or protected space. Support at an organisational level would mean that enough staff are scheduled to work for somebody to leave the floor to meditate for a brief period of time.

I'd say during the day if you were going off to tell somebody in the middle of a shift that you were going off to do your meditation, it would kind of be seen as...not favourable....

There was also a recognised need for a protected space to meditate while in work. Overall, there was a general consensus that support at an organisational level would be paramount to facilitating and promoting staff wellbeing going forward.

I personally think it needs to be part of our paid working day to really promote it to be best practice.

\section{Interpersonal support}

The importance and value of group support was widely recognised, both throughout the training programme and in encouraging daily meditation practice thereafter. With the exception of one, most participants found meditating in a group much easier, more enjoyable and felt they were better able to stay focused, in contrast to meditating alone. This was attributed to a sense of being accountable to other people rather than just being accountable to yourself, as well as an attitude of 'If they can do it, I can do it'.

The importance of the group for the training programme was instrumental to teasing out barriers and enablers to practice.

As a group I think it has been really good to listen to other people's experiences and them relaying the same to you and having a bit of collaboration amongst the group.

Outside of the programme, the group offered support and encouragement to each other to help maintain regular practice, and members of the intervention group looked forward to other members of staff completing the MM programme so that they might have more colleagues to share their practice with.

It will be really interesting when the second group do it because then there will be twice as many of us having done it and hopefully it will just bounce off each other to promote it.

Drop-in group meditations, refresher sessions and other supports such as social network groups were suggested as potential methods to support the staff in their continuation of meditation practice once the training programme ceased. This was considered vital as participants relied quite heavily on the training sessions to refocus and remotivate themselves to engage in MM practice. 


\section{DISCUSSION}

In this study, we conducted semistructured interviews with the objective of harnessing ED staffs' experience of participation in an MM training programme. Our findings lend further support to earlier research on mindbody interventions that use the mantra for healthcare staff, ${ }^{21}$ but also offer some valuable insights and novel contributions to the literature, including perceptions of staff well-being in the ED, the potential contribution of meditation to the personal and professional lives of healthcare professionals, as well as barriers and enablers to implementing well-being programmes in healthcare settings. It is important to note that while the topic guide was referred to in order to enhance questioning and elicit greater depth of information from participants, the themes presented in the results emerged consistently throughout the interview and were not direct outcomes of the probing questions from the guide.

A relentlessly fast-paced culture, inconsistent shift work, and the nature and severity of cases that present to the department on a daily basis make for a profusely stressful working environment. Participants were cognisant of the detrimental impact of such a working environment on their well-being and demonstrated a clear interest in developing a meditation programme within the department. Such reports from participants offer a compelling argument for the implementation of well-being interventions for the ED staff. While previous research has documented the positive impact of mind-body interventions such as mindfulness programmes ${ }^{29}$ and yoga ${ }^{30}$ on burnout and stress in healthcare staff, further research is warranted to validate and compare the MM programme with other approaches.

Similar to other studies on MM, participants reported widespread benefits of MM, including enhanced attention and improved sleep quality. ${ }^{20}$ While some participants found meditation practice useful in helping them to fall asleep, others found that the daily practice improved the quality of their sleep. This has important consequences for the applicability of an MM training programme in an ED. Circadian rhythm disruption (CRD; an interruption to the internal body clock that regulates the 24-hour cycle of biological processes ${ }^{31}$ ) is common among those who carry out shift work. ED staff are particularly susceptible to $\mathrm{CRD}^{31}$ and can experience widespread ill-effects on their well-being as a result. It is possible that MM might buffer the effects of CRD by helping to improve the sleep quality of ED staff, thus boosting their overall health and productivity. Improved focus and attention among practising ED staff might also contribute to enhanced patient safety, quality of care and patient satisfaction. While the impact of the programme on others in the department (patients and working professionals alike) was included as a specific point of discussion in the topic guide, it is notable that insufficient information was provided by participants to elaborate on this. Participants seemed to find it easier to relate the answers of the questions directly to their own experiences, rather than speculating on the potential impact on other people. It is suggested that closed questioning (rather than open-ended questioning) in this regard may have been more useful to elicit such perspectives.

Despite the widely cited benefits, participants of the programme acknowledged difficulties in maintaining the recommended frequency and duration of meditation practice (practice compliance). This has important implications for the future development of this specific training programme and indeed other meditation programmes. Respondents placed a strong emphasis on the importance of building up meditation practice gradually rather than attempting too much too soon. Those who approached the meditation practice target of $20 \mathrm{~min}$, twice daily with an all-or-nothing attitude, appeared to cease practising altogether. Given the reported benefits despite poor adherence to meditation, future research may further explore the minimal duration of practice required in order to elicit positive outcomes for the individual.

A prominent culture of presenteeism ${ }^{32} 33$ suggests that HCPs may have little insight into their own health and well-being, and a dearth of self-care and well-being training in medical school curricula ${ }^{34}$ demonstrates that little emphasis is placed on a preventative or proactive approach. This was reflected in several participants' comments, whereby they felt the need to meditate and adhere to the practice solely for the sake of the research, rather than actually contributing towards their own health. These responses have important implications for the design and delivery of meditation programmes among HCPs and highlight the need for a more proactive, collaborative approach to address self-care and wellbeing training for HCPs.

The findings of this study suggest that further support is required if meditation programmes are to become embedded into busy hospital environments. This support would ideally be offered in both formal and informal settings, with follow-up workshops and retreats offered by specialist facilitators, as well as more casual staff-organised group meditation sessions (daily, weekly or monthly). The provision of these wellness-based programmes will be a cost to the institution. However, the potential cost of absenteeism, early retirement and sick leave as a result of burnout potentially outweighs the cost. A recent Canadian study calculated the total cost of burnout for all practising physicians in Canada to be $\$ 213.1$ million. ${ }^{14}$ Johnson \& Johnson estimated that inhouse wellness programmes cumulatively saved the company $\$ 250$ million on healthcare costs between 2002 and $2008 .^{35}$ It is time that employee wellness programmes become strategically integral to healthcare.

\section{Strengths and limitations}

This qualitative study is to our knowledge the first study of a MM programme for ED staff. We employed a validated method to analyse the data: thematic analysis. Additionally, independent researchers unknown to the participants analysed the interviews to reduce any risk 
of bias. The questions employed in the interviews in this study were open-ended to mitigate against bias; however, response bias is inevitable in qualitative research and must always be taken into consideration. The study participants were diverse in their roles and work experience, implying that these findings could be applied to different healthcare professionals. That being said, participation in both the programme and the interviews was entirely voluntary, which presents the possibility of self-selection bias and limits the extrapolation of findings.

The sample represented the diverse range of roles and experience in the ED; however, a larger sample size would have benefited the study. It is possible that those who volunteered to interview were more enthusiastic about MM than those who did not. As the participants struggled to maintain consistent adherence to MM practice over the period investigated, increased adherence might proffer different findings as well as more robust benefits. Further research in this area is warranted to explore the implications of such a programme on wider hospital operations (including patient safety and quality of care), as well as overcoming the practical limitations of implementing well-being programmes in busy clinical settings.

\section{CONCLUSION}

This study offers indepth qualitative feedback on participants' experience of a MM programme and their perception of ED working conditions. The ED working environment as conveyed by interviewees advocates a desire for such a programme of support for staff. More importantly, however, it supports and contextualises quantitative research that demonstrates concerning levels of burnout and stress in this particular occupational setting, ${ }^{34}$ highlighting an urgent need for action. Participants' unique insight into their perception of the meditation practice suggests that by way of improved attention, awareness and coping skills, MM may have an extended impact on wider healthcare operations, including enhanced HCP-patient interaction, quality of care and patient safety. A flexible approach to the length and regularity of meditation practice is of importance when attempting to integrate sustainable practice among HCPs in the ED. Finally, support from the organisation is not only necessary for sustained practice, but should be viewed as a strategic imperative along with other approaches focused on improving workplace well-being.

Contributors CO'L, RB, BW, LP, PJD, GM, CW and AC were involved in conceiving and designing the study. Data collection was carried out by $C 0^{\prime} \mathrm{L}$. JL and LP were responsible for data analysis and interpretation. $J L$ wrote the first draft of the manuscript. CO'L, RB, BW, LP, PJD, GM, CW and AC contributed to subsequent drafts and were involved in the critical revision of the article for important intellectual content. All authors approved the final version of the article to be published.

Funding This research was sponsored by the Health Service Executive.

Competing interests None declared.

Patient consent Not required.

Ethics approval Institutional ethics committee approval was in place (Tallaght Hospital/St James' Hospital Joint Research Ethics Committee).
Provenance and peer review Not commissioned; externally peer reviewed.

Data sharing statement As per the ethics approval, the data will not be shared outside of the participating research institutions. Any sharing of the data beyond the group will be subject to review by the host institution (Royal College of Physicians of Ireland) and to independent research ethics application. Any queries on how to access the data set should be directed to the corresponding author or research@ rcpi.ie.

Open access This is an open access article distributed in accordance with the Creative Commons Attribution Non Commercial (CC BY-NC 4.0) license, which permits others to distribute, remix, adapt, build upon this work non-commercially, and license their derivative works on different terms, provided the original work is properly cited, appropriate credit is given, any changes made indicated, and the use is non-commercial. See: http://creativecommons.org/licenses/by-nc/4.0/.

\section{REFERENCES}

1. Schrijver I. Pathology in the medical profession?: taking the pulse of physician wellness and burnout. Arch Pathol Lab Med 2016;140:976-82.

2. Aiken LH, Sermeus W, Van den Heede K, et al. Patient safety, satisfaction, and quality of hospital care: cross sectional surveys of nurses and patients in 12 countries in Europe and the United States. BMJ 2012;344:e1717.

3. Shanafelt TD, Boone S, Tan L, et al. Burnout and satisfaction with work-life balance among US physicians relative to the general US population. Arch Intern Med 2012;172:1377-85.

4. Hayes B, Walsh G, Prihodova L. National study of wellbeing of hospital doctors in Ireland. Dublin: Royal College of Physicians of Ireland, 2017.

5. Aditya S, David FE, Han-Chung H. The moderated relationship between job burnout and organizational cynicism. Management Decision 2014;52:482-504.

6. Ahola K, Hakanen J, Perhoniemi R, et al. Relationship between burnout and depressive symptoms: A study using the personcentred approach. Burn Res 2014;1:29-37.

7. van der Heijden F, Dillingh G, Bakker A, et al. Suicidal thoughts among medical residents with burnout. Archives of Suicide Research 2008;12:344-6.

8. Dyrbye LN, Thomas MR, Massie FS, et al. Burnout and suicidal ideation among u.s. medical students. Ann Intern Med 2008;149:334-41.

9. Shanafelt TD, Balch CM, Bechamps G, et al. Burnout and medical errors among american surgeons. Ann Surg 2010;251:995-1000.

10. Shanafelt TD, Bradley KA, Wipf JE, et al. Burnout and self-reported patient care in an internal medicine residency program. Ann Intern Med 2002;136:358-67.

11. Dewa CS, Loong D, Bonato S, et al. The relationship between physician burnout and quality of healthcare in terms of safety and acceptability: a systematic review. BMJ Open 2017;7:e015141.

12. Lu DW, Dresden S, McCloskey C, et al. Impact of burnout on selfreported patient care among emergency physicians. West J Emerg Med 2015;16:996-1001.

13. Michie S, Williams S. Reducing work related psychological ill health and sickness absence: a systematic literature review. Occup Environ Med 2003;60:3-9.

14. Dewa CS, Jacobs P, Thanh NX, et al. An estimate of the cost of burnout on early retirement and reduction in clinical hours of practicing physicians in Canada. BMC Health Serv Res 2014;14:254-54.

15. Silver MP, Hamilton AD, Biswas A, et al. A systematic review of physician retirement planning. Hum Resour Health 2016;14:67.

16. Thimmapuram J, Pargament R, Sibliss K, et al. Effect of heartfulness meditation on burnout, emotional wellness, and telomere length in health care professionals. J Community Hosp Intern Med Perspect 2017;7:21-7.

17. Cutshall SM, Wentworth LJ, Wahner-Roedler DL, et al. Evaluation of a biofeedback-assisted meditation program as a stress management tool for hospital nurses: a pilot study. Explore 2011;7:110-2.

18. Easwaran E. Strength for the storm: creating calm in difficult times. Tomales, CA: Nilgiri Press, 2005.

19. Frequent BJE. Silent mantram repetition: a jacuzzi for the mind. Advanced Emergency Nursing Journal 2005;27:163-6.

20. Bormann JE, Oman D, Kemppainen JK, et al. Mantram repetition for stress management in veterans and employees: a critical incident study. J Adv Nurs 2006;53:502-12.

21. Bormann JE, Walter KH, Leary S, et al. An internet-delivered mantram repetition program for spiritual well-being and mindfulness for health care workers. Spiritual Clin Pract 2017;4:64-73. 
22. Bormann JE, Becker S, Gershwin M, et al. Relationship of frequent mantram repetition to emotional and spiritual well-being in healthcare workers. J Contin Educ Nurs 2006;37:218-24.

23. World Health Organisation, 2017. Healthy workplaces: a WHO global model for action. http://www.who.int/occupational_health/healthy workplaces/en/

24. Johnson RB, Onwuegbuzie AJ. Mixed methods research: a research paradigm whose time has come. Educational Researcher 2004;33:14-26.

25. Bryman A. Integrating quantitative and qualitative research: how is it done? Qualitative Research 2006;6:97-113.

26. Morgan P, Simpson J, Smith A. Health care workers' experiences of mindfulness training: a qualitative review. Mindfulness 2015;6:744-58.

27. Dunne PJ, O'Leary C, Prihodova L, et al. Feasibility study protocol to examine the role of mantra meditation at reducing psychological distress in emergency department staff. Int J Clin Trials 2017;4:88-95.

28. Braun V, Clarke V. Using thematic analysis in psychology. Qual Res Psychol 2006;3:77-101.
29. Goodman MJ, Schorling JB. A mindfulness course decreases burnout and improves well-being among healthcare providers. Int $J$ Psychiatry Med 2012;43:119-28.

30. Alexander GK, Rollins K, Walker D, et al. Yoga for self-care and burnout prevention among nurses. Workplace Health Saf 2015;63:462-70. quiz 71.

31. Kuhn G. Circadian rhythm, shift work, and emergency medicine. Ann Emerg Med 2001;37:88-98.

32. Hayes B, Fitzgerald D, Doherty S, et al. Quality care, public perception and quick-fix service management: a Delphi study on stressors of hospital doctors in Ireland. BMJ Open 2015;5:e009564.

33. Oxtoby $\mathrm{K}$. Why doctors need to resist "presenteeism". BMJ 2015;351.

34. Minford EJ, Manning CL. Current status and attitudes to self-care training in UK medical schools. J Compassionate Health Care 2017;4:3.

35. Berry LL, Mirabito AM, Baun WB, 2010. What's the hard return on employee wellness programs?: harvard business review. www. hbr.org/2010/12/whats-the-hard-return-on-employee-wellnessprograms 